\title{
ENCENAÇÃO DA EDUCAÇÃO NAS CARTAS DE LEITORES
}

\section{Seção carta dos leitores discute educação e revela-se espaço de diálogo com o público e fonte de notícias}

Reivindicações, protestos, análises e comentários sobre temas relativos à educação, especialmente a pública, aparecem com freqüência num espaço reservado pelos jornais para a manifestação de seus leitores: o destinado à publicação das cartas. Os jornais assumem, assim, o papel de mediadores do debate público, possibilitando a encenação de um diálogo que não teria outro lugar para ocorrer.

Analisar a encenação da educação na seção das cartas dos leitores é a proposta da pesquisa $A$ encenação da educação nas cartas dos leitores, desenvolvida como parte de trabalho de mestrado em Educação, defendido em março de 1998, na PUC/RJ. No estudo, foram reunidas 326 cartas de leitores publicadas entre os meses de janeiro e junho de 1996, nos jornais O Globo, Jornal do Brasil e $O$ Dia, que tratavam de assuntos relativos à educação. Os três jornais foram escolhidos por registrarem as maiores vendas de exemplares no Rio de Janeiro e apresentarem propostas editoriais distintas.

Encenar quer dizer levar à cena, colocar em cena, em evidência. Mas também significa representar, interpretar, desempenhar

\section{A AUTORA \\ Élida Vaz}

Jornalista, Mestre em Educação pela PUC/RJ, Coordenadora de Publicações da Diretora de Comunicação Social da Universidade do Estado do Rio de Janeiro - UERJ. $E$ mail: elida@uerj.br determinado papel. Ambas as definições devem ser levadas em conta na análise proposta neste trabalho.

Os jornais, ao abordarem a educação em seu noticiário e selecionarem cartas de leitores a esse respeito, colocam o tema em evidência, em cena, em discussão. Por outro lado, o processo de produção do noticiário e das cartas, resultado de uma série de filtros que envolvem a seleção do que é ou não publicável, acaba por transformar o seu conteúdo em uma representação do real. Não é mais a realidade que está ali presente, mas a interpretação que se tem dela.

Um olhar mais atento sobre as cartas que tratam do tema educação revela diferentes personagens, cada qual desempenhando um papel próprio. Aos cidadãos, cabe a tarefa de reivindicar, de cobrar providências, de exercer o direito de cidadania. As autoridades, por sua vez, se dão ao direito de escolher sobre o tema que querem discutir, deixando muitos dos reclamos sem resposta, numa posição de poder, de superioridade. Já os jornais desempenham o papel de mediadores do debate, estimulando a discussão e, assim, produzindo fatos que serão abordados em seu noticiário.

A educação encenada nas cartas dos leitores é resultado de um mundo que nos chega editado, como observa Maria Aparecida Bacce$\mathrm{ga}$, ao analisar a relação entre Educação e Comunicação: "O mundo que nos é trazido, que conhecemos e a partir do qual refletimos é um 
mundo que nos chega editado, ou seja, ele é redesenhado num trajeto que passa por centenas, às vezes milhares de filtros até que 'apareça' no rádio, na televisão, no jornal. (...) São esses filtros - instituições e pessoas - que selecionam o que vamos ouvir, ver ou ler; que fazem a montagem do mundo que conhecemos"'.

Mergulhar nas cartas, identificar os temas mais focalizados bem como a forma de abordagem utilizada pelos autores são algumas das propostas deste trabalho. $O$ resultado é a construção do mapa das discussões sobre educação registradas nos jornais, nos quais prevalecem os reclamos dos leitores, especialmente no que diz respeito à defesa do pleno funcionamento da escola pública e da importância desta ação.

Os problemas abordados não costumam ser diferentes dos apontados há anos para explicar o caos do sistema educacional brasileiro: baixos salários, desestímulo à carreira do magistério, falta de investimentos, entre outros, podem servir para revelar a desatenção com que as autoridades tratam do assunto, embora em seus discursos ressaltem sempre ações em sentido contrário.

As cartas mobilizam, devido ao impacto que a mídia tem sobre a formação da opinião pública. Ao informar, a mídia também forma conceitos e opiniões que influenciam na imagem pública das autoridades e de quem é abordado em seu noticiário.

Desde o seu surgimento, até os dias de hoje, a imprensa apresenta-se como porta-voz dos anseios de uma parcela da população potencialmente significativa na formação da opinião pública e no estabelecimento do debate em torno de alguns temas. É o que observa Luís Garcia, jornalista e editor do jornal $O$ Globo: "Acredito que uma das mais importantes atribuições da imprensa hoje seja proporcionar o debate. Apresentar-se perante o cidadão dizendo: há tantos caminhos por aí. Escolha o seu. Mas não conseguimos nos livrar do vício de, direta ou indiretamente, abertamente ou com extrema sutileza, dizer ao cidadão 'o caminho é este. O resto não interessa","2 .

Ao insistir em determinados temas ou omitir outros, a imprensa acaba influenciando na escolha do que será discutido pela sociedade e, até mesmo, na forma como o assunto será abordado. No caso da educação, foi possível identificar uma relação direta entre o que os leitores escrevem e o que o noticiário prioriza. Há um movimento de alimentação permanente entre o conteúdo do noticiário e das cartas e vice-versa, como será visto mais adiante.

\section{ESPAÇO DE LUTA}

Cely, Eduardo, Valéria, Vânia são alguns dos muitos professores que escrevem aos jornais para reclamar dos baixos salários e do desestímulo para seguirem adiante no magistério. Há também Luciana, José, Antônio que, como tantos outros alunos e pais, recorrem a este espaço para protestar contra a falta de professores, pedir providências quanto ao pleno funcionamento das escolas, enfim, tornar públicos problemas que enfrentam no dia-a-dia, bem como suas preocupações em relação ao futuro da escola, especialmente a pública. Muitos outros anônimos cidadãos também fazem da seção destinada às cartas dos leitores o palco de suas lamentações, análises e expectativas.

\footnotetext{
1. BACCEGA, Maria Aparecida. Do mundo editado à construção do mundo. Comunicação \& Educação. São Paulo: CCA-ECAUSP/ Moderna, ano 1, n. 1, set./dez. 1994. p. 7.

2. GARCIA, Luís. Era uma vez. In: RITO, L., ARAÚJO, Maria E., ALMEIDA, José Mendes de A. (orgs.) Imprensa ao Vivo. Rio de Janeiro: Rocco, 1989. p. 27.
} 
Nesta teia que se forma, jornais e leitores acabam por desempenhar papéis distintos. De acordo com Marialva Barbosa, o jornal, ao se colocar como intermediário possível entre o público e a sociedade política, cria uma autoidentidade peculiar para se afirmar como "o lugar de difusão da verdade" 3 . Tendo como base as formulações de Jürgen Habermas, os jornais agem dentro da lógica de mediadores do debate público, intermediando as discussões travadas entre os cidadãos comuns e aqueles que detêm o poder, enquanto representantes do Estado ${ }^{4}$. Ao analisar a relação entre imprensa, poder e público, usando como referência diários que circularam entre $1880 \mathrm{e}$ 1920, no Rio de Janeiro, Marialva Barbosa aponta ainda o que os leitores buscam nos periódicos: " $(. .$.$) o seu mundo, visualizar-se$ nesse mundo; encontrar parâmetros da sua existência; recordar o passado; se inserir, ao mesmo tempo, num mundo novo; polemizar; sentir-se atualizados e, portanto, participativos; ser modernos; encontrar temas interessantes para as conversações; visualizar a fantasia ou transformar a sua leitura em fantasia"s.

Os jornais, por sua vez, reservam espaço nas páginas consideradas mais nobres para publicar as cartas de seus leitores e procuram criar cada vez maior proximidade com eles, através de pesquisas e outras ações. Tentam, assim, demonstrar, seguidamente, que são os leitores o foco principal de suas atenções, bem como determinadores do conteúdo diário do que é noticiado. É uma busca de legitimação do papel de mediador do debate, encenado pelos meios de comunicação.

De acordo com Juarez Bahia, o motivo de os jornais darem espaço para que os leitores se manifestem é estabelecer uma relação informal, útil e representativa. "As cartas embutem ainda um inequívoco objeto democrático e quanto maior for o grau de participação dos leitores maior será a intensidade do debate que elas costumam provocar. Hoje, em qualquer país e em qualquer sistema de governo, as cartas dos leitores concorrem ativamente para qualificar o papel da imprensa" 6 .

Este mesmo autor observa ainda que as cartas servem para traduzir níveis de receptividade a determinadas posições ou notícias veiculadas pelos jornais, bem como para testar as formas de estilo adotadas e $\mathrm{o}$ alcance do conteúdo, assim como para denotar tendências políticas, partidárias, éticas ou de cidadania.

\section{ALGUNS RESULTADOS}

Das 326 cartas reunidas na pesquisa, 122 foram encaminhadas, no período de janeiro a junho de 1996, ao jornal $O$ Dia, o que representa $37,4 \%$ do total. Outras 106 foram encaminhadas, no mesmo período, ao Jornal do Brasil, correspondendo a 32,5\%; e outras 98 ao jornal $O$ Globo, ou 30,1\%. O Dia mostra-se, assim, como o jornal que mais espaço deu à educação nas cartas dos leitores no período analisado.

Dividindo-se as 326 cartas pelos 181 dias correspondentes aos seis meses, chegase ao resultado de quase duas cartas sobre educação publicadas por dia pelos três jornais. É mais um dado sobre a importância do tema para leitores e editores. O que se percebe também nesta pesquisa é que o ato de recorrer aos jornais é muito mais indivi-

\footnotetext{
3. BARBOSA, Marialva. Imprensa, poder e público: os diários do Rio de Janeiro (1880-1920). Intercom Revista

Brasileira de Comunicação. v. XX, n. 2. São Paulo, julho/dezembro 1997. p. 99.

4. HABERMAS, Jürgen. Mudança estrutural da esfera pública. Rio de Janeiro: Tempo Brasileiro, 1984.

5. BARBOSA, Marialva. Imprensa... op. cit. p. 99.

6. BAHIA, Juarez. Jornal, história e técnica - história da imprensa brasileira. São Paulo; Ática, v. I e II. 1990. p. 71.
} 
dual do que coletivo. Apenas $4,3 \%$ do total de cartas analisadas, o que corresponde a um universo de 14 correspondências, era assinada por mais de um autor, constituindo-se assim como cartas coletivas. A maioria, 312 , era de apenas um autor.

Percebe-se também uma relação direta entre as cartas publicadas e os temas relativos à educação, enfocados na maior parte das notícias veiculadas pelos jornais. Há um movimento de circularidade, de alimentação permanente entre as cartas e o noticiário. As cartas tanto produzem o noticiário quanto são por ele produzidas. Foi possível verificar, ainda, que $18,3 \%$ das correspondências publicadas nos três jornais se referiam a notícias e $14,4 \%$ a outras cartas publicadas.

O caso da jovem estudante Luciana Soares da Silva, cuja carta foi publicada no dia 21 de março na seção Opinião dos leitores, do Jornal do Brasil, é um bom exemplo da relação direta que se estabelece entre a opinião dos leitores e o noticiário, bem como do propósito de debate que o espaço apresenta neste jornal. Quatro dias depois de a carta de Luciana ser publicada, a estudante transformou-se em personagem de entrevista de página inteira do Jornal do Brasil, em sua edição de domingo. $\mathrm{E}$ ao longo das edições seguintes em que a carta de Luciana foi publicada, várias outras correspondências apareceram na seção com referências explícitas ao drama relatado pela estudante, pela falta de perspectivas em relação ao seu futuro devido à falta de professores nas escolas.

Na pesquisa foi possível observar que muitas pessoas recorrem a mais de um jornal para expressarem seus problemas ou opiniões. Escrevem com frequiência para até os três jor- nais envolvidos neste estudo. Em geral, essas pessoas abordam o mesmo assunto. O sistema público de ensino foi o mais citado, com 75,5\% de ocorrências. Quase 25\% dos autores que se referiram à rede pública o fizeram sem especificar a esfera, enquanto $22,7 \%$ trataram da rede estadual, $18,4 \%$ da rede municipal e $9,5 \%$ da rede federal de ensino.

Tais dados revelam a importância que se atribui à escola pública como agente de transformação numa sociedade tão cheia de diferenças e desigualdades como a brasileira. A carta do leitor Eduardo Varela, publicada no Jornal do Brasil de 18 de março, resume bem o propósito da luta em defesa da escola pública travada no espaço reservado às cartas dos leitores pelos jornais, como pode ser observado no texto de Varela: “(...)Nossa luta pelo ensino público de qualidade em todos os níveis é justamente para que a classe social de alguém jamais seja um impeditivo para seu desenvolvimento (...)".

Apenas $10,7 \%$ dos autores referem-se às escolas particulares e, neste caso, o tema mais abordado é relativo às mensalidades, especialmente reclamações e críticas contra aumentos considerados abusivos. Em geral, esses pais reclamam dos índices de aumento adotados por universidades e escolas particulares e há até mesmo os que chegam a enviar planilhas aos jornais para confirmar o que denunciam. Outros 13,8\% dos leitores que escreveram aos jornais no período focalizado na pesquisa não se referiram especificamente à rede pública ou particular. Essas cartas tratavam da educação de uma forma geral.

Entre o grupo de autores que se identifica quanto ao papel ou função que desempenha na rede municipal são os professores que aparecem em maior número - 64. Eles correspondem a $35,5 \%$ dos 180 que apresentam, no teor das cartas, informações relativas ao papel que exercem no sistema de ensino e representam quase $20 \%$ 
do total das 326 cartas analisadas. Os pais também aparecem com frequiência considerável ( 37 ou $20,6 \%$ entre os que se identificam).

Foram encontradas apenas 14 cartas assinadas por integrantes de associações, seja de pais ou de profissionais de educação. Isso pode indicar, no caso das associações de pais, a pouca adesão a entidades deste tipo bem como a falta de articulação de seus representantes para ocupar espaço no debate que se estabelece a respeito da educação nas cartas dos leitores. Já no caso das associações profissionais, prevalece a presença do Sindicato dos Profissionais de Educação do Rio de Janeiro (Sepe), entidade profissional que representa professores e funcionários da rede pública de ensino.

Os assuntos mais abordados nas cartas pelos leitores também podem indicar as reivindicações mais urgentes para a sociedade que se mobiliza através deste espaço. Na análise das cartas foram levados em conta todos os temas tratados pelos autores e não apenas o que pudesse ser considerado mais importante. Desta forma, foi possível traçar um mapa de todas as discussões travadas pelos leitores, pois alguns abordam mais de um tema numa mesma carta.

Os salários aparecem com o maior número de citações, com um total de $24,2 \%$. Em segundo lugar, aparece o descaso com a educação, seguida da falta de professores. A falta de professores é focalizada em 15\% das cartas, enquanto em outras $9,2 \%$ os autores referem-se à falta de recursos.

As redes estadual e municipal de ensino do Rio de Janeiro são as que apresentam o maior número de cartas que tratam de salários: 29 e 19 respectivamente. Já o descaso com a educação é um tema mais observado nas cartas que enfocam o sistema estadual de ensino ( 15 ocorrências). A falta de professores também é um tema que aparece com maior frequiência nas cartas que se referem às escolas estaduais ( 24 contra seis do município).

Salário é o tema mais abordado pelos professores, as maiores vítimas da política adotada pelos governos. Quase $61 \%$ dos professores que se identificam nas cartas tratam deste tema. Entre os profissionais de educação, as três cartas referentes a este grupo publicadas entre janeiro e junho de 1996 também enfocavam a baixa remuneração.

Os alunos e os pais, por sua vez, escrevem aos jomais para tratar, principalmente da falta de professores $(45,8 \%$ e $29,7 \%$, respectivamente). Mas também se solidarizaram com os docentes, na reivindicação por melhores salários. Tanto pais quanto alunos enfocam ainda inúmeros outros temas, como a educação como saída para a crise social, privatização do ensino etc.

Já as autoridades abordam em suas cartas um número enorme e variado de temas, como avaliação de alunos, violência nas escolas, uso de recursos públicos, concurso que, por registrarem baixa frequiência isoladamente, foram agrupados na categoria outros. Os temas mais tratados por pais, alunos e professores quase não são abordados pelas autoridades: a falta de recursos e salários foram localizados em $10,7 \%$ das cartas, enquanto o descaso com a educação apareceu em apenas 3,6\% das cartas escritas por autoridades.

Se são os problemas que prevalecem entre os temas mais citados pelos leitores que recorrem aos jornais, através de cartas, como se viu anteriormente, a forma de abordagem utilizada com mais frequiência é a crítica, registrada em $48,5 \%$ das cartas. Também há considerável número de cartas ( $27 \%$ ) cujos autores preferem analisar a situação. Há ainda que se ressaltar a presença de denúncia, apelo, pedido de esclarecimento, convocação, desabafo e alerta como formas de abordagem bastante utilizadas pelos leitores, enquanto apenas $4,9 \%$ escrevem para elogiar . 


\section{TERRITÓRIO DE CONQUISTA}

Pode-se perceber que mais do que projetos de grande envergadura, a sociedade, em geral, quer que a escola, especialmente a pública, funcione e cumpra sua finalidade mais primordial: a de ensinar e dar oportunidades iguais, independente da origem social de seus alunos.

Percebe-se na pesquisa, também, que as cartas em geral são dirigidas às autoridades. Os leitores demonstram saber a quem cabe determinadas responsabilidades. Assim, prefeitos e secretários são citados nominalmente em várias cartas que cobram providências no âmbito da rede municipal; governadores e auxiliares no caso das unidades de ensino estadual; e até o presidente da República e o ministro da Educação quando a discussão se volta para a esfera federal, que inclui as universidades e também a definição da política educacional do país.

Foi possivel observar, na pesquisa, que existe uma especificidade do trabalho desenvolvido pelos jornalistas, muito mais motivada pelos acontecimentos do dia-a-dia do que executadas com o propósito de dominar ou manipular a opinião pública.

Robert Darnton, jornalista e historiador, ao relatar a sua própria experiência como repórter do New York Times, mostra que há muito menos lógica na tarefa de se produzir todos os dias um jornal do que qualquer pessoa possa supor. O que o autor procura demonstrar em suas análises é a considerável distância que existe entre o que costumam formular os teóricos da área de ciências sociais, a respeito do trabalho jornalístico e a tarefa em si. Para Darnton, o trabalho desenvolvido diariamente pelos jornalistas, em condições específicas, é, muitas vezes, o que determina os procedimentos que acabam sendo adotados, independente da lógica que cada veículo possua e dos interesses que tenha.

"Sociólogos, cientistas políticos e especialistas em comunicação têm produzido uma vasta literatura sofre os efeitos dos interesses econômicos e tendências políticas no jornalismo. No entanto, parece-me que eles não têm conseguido entender a maneira como trabalham os repórteres. O contexto do trabalho modela o conteúdo da notícia, e as matérias também adquirem forma sob a influência de técnicas herdadas de contar história"

Com isso, o autor não nega que os jornais, como empresas que visam ao lucro, tenham interesses além de satisfazer os seus leitores. Mas o que ele ressalta, em sua análise, é que os jornalistas, encarregados da produção diária dos jornais, não escrevem para imagens de pessoas invocadas pela ciência social, como se costuma acreditar, mas sim para outros jornalistas. Isto porque a concorrência é determinante dentro de cada redação.

"Nosso principal 'grupo de referência' como se poderia dizer na teoria da comunicação, encontrava-se espalhado em torno de nós na sala de redação, ou buraco da cobra, como dizíamos. Sabíamos que os primeiros a cair em cima de nós seriam nossos colegas, pois os repórteres são os leitores mais vorazes, e precisam conquistar seu status diariamente, ao se exporem aos seus colegas de profissão"8.

As cartas, portanto, colocam em cena a educação, nas reivindicações dos usuários dos serviços oferecidos pelo estado, no caso das 
escolas públicas, e pelas escolas privadas. Sem dúvida, as discussões travadas pela imprensa a respeito do tema ainda deixam a desejar, especialmente pela superficialidade com que são abordados ${ }^{9}$, bem como pela repetição dos mesmos problemas continuamente. Isso leva, muitas vezes, à perda da expectativa de mudança, como revelam, vários autores, em suas cartas. Mesmo assim, os leitores fazem questão de se manifestar, especialmente na defesa da escola pública, demonstrando, desta forma, acreditar estarem agindo como cidadãos.
Resumo: $\mathrm{O}$ artigo trata de pesquisa de mestrado, defendida em 1998, na PUC/RJ, sobre as cartas de leitores enviadas a três grandes jornais do Rio de Janeiro - O Dia, Jornal do Brasil e O Globoque têm a educação como temática. A autora analisa como as preocupações que os jornais têm com o tema e, também, como as notícias sobre educação, veiculadas nos jornais, vão pautando as discussões feitas através das cartas. Revela que a seção de cartas dos leitores é um espaço importante de diálogo entre o jornal e a sociedade, sendo palco das principais discussões sobre a educaçâa, que devem ser feitas pelo conjunto da sociedade.

Palavras-chave: O Dia, Jornal do Brasil, O Globo, carta dos leitores, educação
Abstract. The article talks about a master's degree research project, defended in 1998, at PUC/RJ, on reader letters, having education as their theme, sent to three major Rio de Janeiro newspapers, O Dia, Jornal do Brasil and $O$ Globo. The author analyzes how these letters outline the concerns newspapers have on the theme and also how the news about education, published by the newspapers, outline the discussions made through the letters. It reveals that the reader letter section is an important dialogue space between the newspaper and society, and that this is one of the main stages for discussion on education, a discussion that must be undertaken by society as a whole.

Key words: O Dia, Jornal do Brasil, O Globo, reader letters, education

9. A esse respeito, vale consultar a dissertação de inestrado $O$ "Estado" da Educaçâo na "folha" de jomal - como os jornais de grande circulaçâo abordam a questão educacional. de Belarmino Cesar Guimarães da Costa, defendida em 1993, na Universidade Federal de São Carlos, São Paulo. Em síntese, o autor conclui que "os meios de comunicação banalizam o ser humano, dessensibilizam a sociedade diante da barbárie de múltiplos atos de violência cotidiana explorados com sensacionalismo pela imprensa". 